\title{
Comparative Study on Growth and Developmental Model of Indigenous Chicken Breeds in China
}

\author{
Zhenhua Zhao, Shoufeng Li*, Huayun Huang, Chunmiao Li, Qianbao Wang, Longgang Xue \\ Institute of Poultry Science, Chinese Academy of Agriculture Science, Yangzhou, China \\ Email: ${ }^{*}$ zzlsf3333@126.com
}

Received 2 March 2015; accepted 21 April 2015; published 28 April 2015

Copyright $(02015$ by authors and Scientific Research Publishing Inc.

This work is licensed under the Creative Commons Attribution International License (CC BY).

http://creativecommons.org/licenses/by/4.0/

(c) (i) Open Access

\begin{abstract}
The growth and development regularity and genetic parameters were described in three types of indigenous chicken in China, Shaobo, Huaixiang and Youxi Chicken, by 3 nonlinear mathematics models, Logistics, Gompertz and Bertalanfy, according to the data of Body Weight from 1 week to 10 weeks. The results showed that the growth process of the three breeds could be illustrated well by three models, and the indices of fitness were very high (more than 0.99). Among the 3 models, Gompertz model was the best for its less bias from practice. The inflexions of growth were 5.98, 5.11 and 6.16 weeks of age, and body weights were $2115.77 \mathrm{~g}, 1499.08 \mathrm{~g}$ and $1409.62 \mathrm{~g}$, respectively in Shaobo Chicken, Huaixiang Chicken and Youxi Chicken.
\end{abstract}

\section{Keywords}

Indigenous Chicken, Growth Curve, Fitting Model, Weight

\section{Introduction}

The chicken raising is a flourishing part of modern poultry industry. There are plenty of chicken resources in China, and Chinese indigenous chicken is characterized with good meat quality and flavor, strong antidisease and good endurance [1]. How to utilize these genetics resources, enhance the exploitation of indigenous chicken and promote the income of farmers is important in chicken industry. The growth curve reflects the whole or part of the animal growth process. Exploration of growth and development curves can dynamically understand and predict the growth and development of animals [2] [3]. It can also provide guidance for early breeding, so the estimation of early growth and development regularity and genetic parameters suggest important significance [4]

"Corresponding author.

How to cite this paper: Zhao, Z.H., Li, S.F., Huang, H.Y., Li, C.M., Wang, Q.B. and Xue, L.G. (2015) Comparative Study on Growth and Developmental Model of Indigenous Chicken Breeds in China. Open Journal of Animal Sciences, 5, 219-223. 
[5]. Generally, the growth of animal is nonlinear, so the nonlinear mathematics model is useful for describing the animal's growth regularity [6] [7] and setting up a growth model under the ideal environment.

The advantage of the models is to reduce a series of age-weight data to a few parameters in growth equation and to eliminate the effects of errors effectively [8] [9]. In this study, the estimation on three type of Chinese indigenous chicken, big, medium and mini, was conducted. Different growth models were used for growth development regularity to get the optimum parameters and the estimate growth, inflection age and bodyweight, in order to provide a scientific basis for the protection, exploitation and utilization of Chinese indigenous chicken.

\section{Materials and Methods}

\subsection{Experimental Animals}

392 Shaobo Chicken, 305 Huaixiang Chicken and 348 Youxi Chicken were selected from Gaoyou breeding farm in Jiangsu Province, China. Chicken were brooded inside for the first 2 weeks, then raised outside. Food and water were supplied ad libitum. The ingredients of nutrition were listed in Table 1. Chicken were weighed at 1 week intervals to 10 weeks.

\subsection{Mathematical Growth Models}

Logistics: $\mathrm{W}_{\mathrm{t}}=\mathrm{A} /\left(1+\mathrm{B} * \exp \left(-\mathrm{C}_{\mathrm{t}}\right)\right)$;

Gompertz: $\mathrm{W}_{\mathrm{t}}=\mathrm{A}\left(1-\mathrm{B} * \exp \left(-\mathrm{C}_{\mathrm{t}}\right)\right)^{3}$;

Bertalanfy: $W_{t}=\operatorname{Aexp}\left(-B * \exp \left(-C_{t}\right)\right)$.

where $\mathrm{W}_{\mathrm{t}}$ was the average weight parameter at age $t$, A was asymptotic bodyweight, $\mathrm{C}_{\mathrm{t}}$ was instant relative growth rate, $\mathrm{B}$ was regulate parameter.

\subsection{Statistics Analysis}

All the data were computed on SPSS statistic software. With the least deviation as the target function the standard convergence was 0.05 and the best estimation was calculated step by step to establish the growth model and calculate the parameters.

\section{Results}

\subsection{The Growth Rate of Chicken}

The regularity of growth change was showed in Table 2. The average gain was less than $10 \mathrm{~g}$ before two week and the growth rate increased from 2 weeks of age. The maximal growth rate appeared during 5 - 9 weeks for Shaobo and Youxi Chicken, whereas 4 - 10 weeks in Shaobo Chicken. The peak appeared in 7 weeks, the maximal average gain was $24.29 \mathrm{~g}$, whereas it was 6 weeks of age in Youxi Chicken and the maximal average gain

Table 1. Ingredients of chicken feed.

\begin{tabular}{ccc}
\hline Nutritional ingredients & $0-5$ weeks & $6-10$ weeks \\
\hline Energy (MJ/kg) & 11.97 & 12.1 \\
Protein (\%) & 20.00 & 18.00 \\
Calcium (\%) & 0.90 & 0.85 \\
Phosphorus (\%) & 0.45 & 0.40 \\
Lysine (\%) & 1.09 & 0.82 \\
Methionine (\%) & 0.28 & 0.21 \\
Salt (\%) & 0.37 & 0.37 \\
\hline
\end{tabular}


was $23.74 \mathrm{~g}$. The early growth rate was less than Shaobo and Youxi Chicken for Huaixiang Chicken. The maximal average gain peak appeared in 7 weeks, which was only $18.70 \mathrm{~g}$.

\subsection{The Comparison of Different Models}

The estimation results were showed in Table 3. It indicated that the growth curves could be fitted by all nonlinear curves model because the indices of fitness were up to beyond 0.99. The parameters A and C of Gompertz Model, namely asymptotic bodyweight and instant relative growth rate were close to the practice. The values of A for Shaobo, Huaixiang and Youxi Chicken were $2968.26 \mathrm{~g}, 2423.34 \mathrm{~g}$ and $2806.50 \mathrm{~g}$ respectively; the parameter B of these chicken were 2.82, 3.14 and 2.93 respectively; and the parameter $\mathrm{C}$ were $0.12,0.16$ and 0.12 respectively. For the parameter $\mathrm{C}$, Huaixiang Chicken showed the highest value, which was bigger than the breed practice. Inflection age of growth was 8.64, 7.38 and 8.96 weeks, respectively. The corresponding weights were 1091.93, 718.03 and $1032.45 \mathrm{~g}$ for Shaobo, Huaixiang and Youxi Chicken, respectively. The expected data estimation by Gompertz was close to the practice mostly because of its higher fitness and less bias of predicted

Table 2. Early bodyweight development rule of 3 chicken breeds.

\begin{tabular}{|c|c|c|c|c|c|c|}
\hline \multirow{2}{*}{ Week } & \multicolumn{3}{|c|}{ Average weight (g) } & \multicolumn{3}{|c|}{ Average gain $\left(g \cdot d^{-1}\right)$} \\
\hline & Shaobo Chicken & Huaixiang Chicken & Youxi Chicken & $\begin{array}{l}\text { Shaobo } \\
\text { Chicken }\end{array}$ & $\begin{array}{l}\text { Huaixiangg } \\
\text { Chicken }\end{array}$ & $\begin{array}{l}\text { Youxi } \\
\text { Chicken }\end{array}$ \\
\hline 0 & $39.60 \pm 3.73$ & $29.480 \pm 3.48$ & $35.46 \pm 3.56$ & & & \\
\hline 1 & $81.03 \pm 11.35$ & $71.68 \pm 9.76$ & $84.76 \pm 12.28$ & 5.92 & 6.03 & 7.04 \\
\hline 2 & $148.05 \pm 25.7$ & $113.74 \pm 20.35$ & $151.90 \pm 23.42$ & 9.57 & 6.01 & 9.59 \\
\hline 3 & $240.32 \pm 30.57$ & $161.28 \pm 20.35$ & $247.08 \pm 29.53$ & 13.18 & 6.79 & 13.60 \\
\hline 4 & $362.20 \pm 57.05$ & $217.10 \pm 48.46$ & $358.72 \pm 46.49$ & 17.41 & 7.97 & 15.95 \\
\hline 5 & $519.97 \pm 88.63$ & $281.81 \pm 69.32$ & $512.69 \pm 79.96$ & 22.54 & 9.24 & 22.00 \\
\hline 6 & $682.02 \pm 113.42$ & $354.78 \pm 105.19$ & $678.85 \pm 114.37$ & 23.15 & 10.42 & 23.74 \\
\hline 7 & $852.07 \pm 155.11$ & $485.68 \pm 112.36$ & $825.46 \pm 124.65$ & 24.29 & 18.70 & 20.94 \\
\hline 8 & $1011.81 \pm 179.55$ & $602.94 \pm 142.80$ & $955.42 \pm 169.30$ & 22.82 & 16.75 & 18.57 \\
\hline 9 & $1167.02 \pm 198.25$ & $710.22 \pm 143.72$ & $1083.48 \pm 187.94$ & 22.17 & 15.33 & 18.29 \\
\hline 10 & $1319.93 \pm 234.99$ & $800.53 \pm 182.64$ & $1202.46 \pm 210.06$ & 21.84 & 12.90 & 17.00 \\
\hline
\end{tabular}

Table 3. Estimating results with different non-linear growth models.

\begin{tabular}{|c|c|c|c|c|c|c|c|}
\hline Breed & Model & $\mathrm{A}(\mathrm{g})$ & B & $\mathrm{C}$ & $\begin{array}{l}\text { Index of } \\
\text { fitness }\end{array}$ & $\begin{array}{l}\text { Inflexions of } \\
\text { growth (week) }\end{array}$ & $\begin{array}{l}\text { Inflexions } \\
\text { weight (g) }\end{array}$ \\
\hline \multirow{3}{*}{ Shaobo } & Logistic & 2397.686 & 21.76 & 0.35 & 0.9947 & 8.80 & 1198.843 \\
\hline & Von Bertalanfy & 3685.375 & 1.00 & 0.13 & 0.9961 & 8.45 & 1064.041 \\
\hline & Gompertz & 2968.263 & 2.82 & 0.12 & 0.9989 & 8.64 & 1091.963 \\
\hline \multirow{3}{*}{ Huaixiang } & Logistic & 1832.664 & 19.69 & 0.35 & 0.9947 & 8.29 & 925.588 \\
\hline & Von Bertalanfy & 2354.741 & 1.00 & 0.13 & 0.9976 & 8.45 & 875.011 \\
\hline & Gompertz & 2423.338 & 3.14 & 0.16 & 0.9984 & 7.38 & 718.026 \\
\hline \multirow{3}{*}{ Youxi Chicken } & Logistic & 2237.614 & 17.27 & 0.32 & 0.9922 & 8.90 & 1118.807 \\
\hline & Von Bertalanfy & 3438.403 & 1.00 & 0.13 & 0.9988 & 8.45 & 1018.786 \\
\hline & Gompertz & 2806.504 & 2.93 & 0.12 & 0.9998 & 8.96 & 1032.455 \\
\hline
\end{tabular}


body weight on the given age. These indicated that the Gompertz equation is the optimum model for early growth estimation of three types and provided the reference for growth developmental mechanism of Chinese indigenous chicken breeds.

\section{Discussions}

\subsection{The Economical Characteristics of Three Breeds}

The Shaobo Chicken was bred by institute of poultry science, Chinese academy of agriculture science; it was characterized by a fast growth rate and better feed conversion. The mature bodyweight could weigh up to $2000 \mathrm{~g}$, which was one of the best meat types in chicken breeds in China. Huaixiang Chicken belongs to the medium meat type, originating in Guangdong province, the mature weight can reach $1500 \mathrm{~g}$, it is an early mature type and is famous for its thin skin and high meat quality. Youxi Chicken was small the type and the weight can reached $1200 \mathrm{~g}$ at 70 days of age. Youxi Chicken belongs to the meat type and originating in Yuannan and Guangxi province, it was characterized for meat quality, strong antidisease and good endurance. This breed can keep high productivity under the cold climate and crude feed, which was the rare breed with high productivity. These three breeds together have the largest feed number in China of indigenous chicken breeds for meat types and are the main breeds used in chicken industry. But till now most researches focused on feed technology and husbandry, few related to the growth regularity [10]. This study would set up a good basis for the genetic selection of chicken breed and promote the prosperity of chicken industry.

\subsection{Early Growth and Development of Different Chicken}

For Shaobo and Youxi Chicken, the growth rate increased from 2 weeks of age and the maximal growth rate appeared during 3 - 9 weeks, whereas it was 6 - 8 weeks in Huaixiang Chicken. The peak appeared in 7 week, which was similar to the previous study [11]-[13].

\subsection{The Comparison of Different Models}

Up to present, there are many researches on the poultry growth and development model, of which Logistic, Gompertz and Bertalanfy are the three main models, but different researches implied different models [14]. Due to difference of breeds, environment conditions and other errors, obtaining a good comparison among different research results was difficult [15] [16]. The results indicated that the growth curves could be fitted by three nonlinear curves model, the fitness exceeded 0.99, but the Gompertz model was better model to fit growth curves because of its higher fitness and less bias of predicted body weight on the given age. FU Ruiqi analyzed the bodyweight data of Beijing You Chicken [17], the results showed that the fitness and analysis were feasible for growth curve in Beijing You Chicken using three kinds of models, and Gompertz model was the best. CAO Zan [18] discussed the growth and development rules of Ross 308 broiler with three growth Curve, and Gompertz was better than the other two.

\section{Conclusion}

In this study, 3 nonlinear general models were used to estimate the change regularity of weight in three breeds under the same environment. When these models were compared, the results showed that Gompertz Model was close to the practice, which was the optimum one to estimate the growth and development regularity in early time and was identical to the previous study. According to the raising practice, the use of Gompertz Model and its equation can make a standard of growth and development for indigenous chicken in China. It can also be used to forecast the growth data such as cumulative growth, absolute growth and relative growth, and to confirm the inflection age and feed levels, so as to make productive plans, provide credible academic data for further selection on indigenous chicken and establish the corresponding technology.

\section{Acknowledgements}

The research was supported by the earmarked fund for modern agro-industry technology research system (cars-42-c06), Jiangsu scientific and technological program (BE2014364), Jiangsu scientific and technological program (BE2013386). 


\section{References}

[1] Zhao, Z.H., Xi, J.Z., Jia, Q., Li, S.F. and Huang, H.Y. (2010) Analysis of Genetic Structure and Diversity of Chai Chicken Breed Using Microsatellite Markers. Journal of Animal and Veterinary Advances, 9, 1197-1200.

[2] Grossman, M. (1985) Logistic Growth Curve of Chickens: Heritability of Parameters. Heredity, 76, 459-462.

[3] Fan, Y.G. and Ye, S.Z. (1997) A Study on the Growth Curve and Maximum Profit from Layer-Type Cockerel Chickes. Poultry Science, 38, 445.

[4] Roush, W.B. and Branton, S.L. (2005) A Comparison of Fitting Growth Models with a Genetic Algorithm and Nonlinear Regression. Poultry Science, 84, 494-502. http://dx.doi.org/10.1093/ps/84.3.494

[5] Wang, F., Li, X.C. and Wu, K.B. (2014) Growth Curve and Correlation Analysis on Body Weight and Body Size of Bawang Chicken. Journal of Southern Agriculture, 45, 870-874.

[6] Li, X., Xiao, C.-H. and Yan, G.-H. (2006) Early Growth and Development of Heilongjiang Zi Chicken. Acta Ecologiae Animalis Domastici, 27, 82-85.

[7] Forni, S., Piles, M., Blasco, A., Varona, L., Oliveira, H.N., Lôbo, R.B. and Albuquerque, L.G. (2009) Comparison of Different Nonlinear Functions to Describe Nelore Cattle Growth. Journal of Animal Science, 87, 496-506.

[8] Wang, S.K., Wang, G.Y. and Li, A. (1999) Study on the Growth Models of Fujian White Muscovy Duck. Thesis Volume of the 9th Academic Forum on Nationalwide Poultry, location, date, 35-37.

[9] Aggrey, S.E. (2002) Comparison of Three Nonlinear and Spline Regression Models for Describing Chicken Growth Curves. Poultry Science, 81, 1782-1788. http://dx.doi.org/10.1093/ps/81.12.1782

[10] Liu, H.X., Ji, G.G., Shan, Y.J. and Shu, J.T. (2013) Exploration of Growth Curves for Recessive White Chicken and Qingyuan Patridge Chicken and Correlation Study. Acta Ecologiae Animalis Domastici, 34, 33-37.

[11] Wu, W., Gao, G., E, Z.J. and Lv, W.F. (2004) Study on Breed Specific Properties of Jilin White Chicken. Journal of Economical Animal, 4, 50-56.

[12] Ye, C.-H. and Zhong, R.C. (2005) Studies on Growth Model of Shaobo Chicken. Journal of Shihe Youxi University (Natural Science), 23, 694-697.

[13] Zhu, Z.M., Yang, W. and Xin, Q.W. (2013) Comparative Study on Growth and Developmental Model of Hetian Chicken. Acta Agricuhurae Jiangxi, 25, 66-69.

[14] Aggrey, S.E. (2002) Comparison of Three Nonlinear and Spline Regression Models for Describing Chicken Growth Curves. Poultry Science, 81, 1782-1788. http://dx.doi.org/10.1093/ps/81.12.1782

[15] Sun, G.R., Zhu, Z.M., He, D.G., Gong, S.M. and Shen, H.M. (2006) Development Regularity of Early Body-Weight and the Fitness of Growth Curve on Lai-Chuan cross Chicken. Chinese Journal of Animal Science, 42, 10-12.

[16] Wang, D.Q., Lu L.Z., Ye W.C., Shen J.D., Tao Z.R., Tao Z.L., Ma F.L., Chen Y.C., Zhao A.Z. and Xu J. (2004) Study on the Growth Regularity of Jinyun Muscovy Duck. Zhejiang Journal of Animal Science and Veterinary Medicine, $\mathbf{6}$, 3-5.

[17] Fu, R.Q., Zhao, G.P., Liu, R.R., Huang, H.Y., Zheng, M.Q., Chen, J.L. and Wen, J. (2014) Fitting and Analysis of Growth Curve in Beijing You Chicken. Chinese Poultry, 36, 6-9.

[18] Cao, Z., Chen, G.X., Zhang, S.C., Huang, Z.P. and Gao, Z.H. (2014) Growth Curve Fitting and Growth Rule Prediction of Ross 308 Broiler. Guangdong Agriculture Science, 7, 106-110. 